Fizik / Physics

DOI: $10.21597 /$ jist.756249

Araştırma Makalesi / Research Article

Geliş tarihi / Received: 23-06-2020

Kabul tarihi / Accepted: 22-11-2020

\title{
A Theoretical Study of 2-hydroxyethyl Substituted NHC Precursors Containing ortho-, meta- and para- methylbenzyl: Global Reactivity Descriptors and Prediction of Biological Activities
}

\section{Duygu BARUT CELEPCI ${ }^{1 *}$}

\begin{abstract}
In this work, three 2-hydroxyethyl substituted $N$-heterocyclic carbene (NHC) precursors containing ortho-, meta- and para- methylbenzyl fragments are characterized theoretically. Theoretical calculations are performed to gain insight into these three molecules' electronic properties (HOMOLUMO energy, MEP and global reactivity descriptors) and biological behaviors. Also, atomic charges are calculated and molecular orbital analysis is performed. In order to investigate the stability of the molecules resulting from hyperconjugative interactions and charge delocalization, natural bond orbital (NBO) analysis is used. A predictive study for the biological activities is carried out using PASS (prediction of activity spectra for biologically active structures) online software. Biological activity predictions showed the substance $\mathrm{P}$ antagonist, analgesic and antiinflammatory activities of the compounds.
\end{abstract}

Keywords: N-heterocyclic precursors, DFT, PASS online

${ }^{1}$ Duygu BARUT CELEPCI (Orcid ID: 0000-0003-1581-6208), Dokuz Eylül University, Faculty of Science, Department of Physics, İzmir, Turkey

*Corresponding Author: Duygu BARUT CELEPCİ, e-mail: duygu.barut@deu.edu.tr 
A Theoretical Study of 2-hydroxyethyl Substituted NHC Precursors Containing ortho-, meta- and paramethylbenzyl: Global Reactivity Descriptors and Prediction of Biological Activities

\section{INTRODUCTION}

Carbene precursors such as benzimidazolium salts have attracted great attention in organic chemistry by virtue of its structural and electronic properties (Hopkinson et al., 2014; Sar1 et al., 2018). Especially, the NHC precursors can form complexes almost with all of the transition metals (Dragutan et al., 2007; Nirmala and Viswanathamurthi, 2016) so, they have attracted interest in biological activity studies due to their strong activity in enzyme inhibition studies (Zou et al., 2018). In our previous study, the investigations on the biological activity of 2-hydroxyethyl substituted NHC compounds containing methylbenzyl substituents show that these compounds have exhibited biological activity (Erdemir et al., 2018). Indeed, biological experiments are often limited in terms of sample, time and cost. Besides, DFTbased reactivity descriptors are advantageous and generally be consistent with the experimental observations (Chattaraj et al., 2003). In recent years, the prediction of the reactivity of chemical systems is one of the main objectives of theoretical chemistry. Density functional theory (DFT) has been quite successful in providing the theoretical groundwork of this purpose. For analyzing and understanding the biological reactivity of the chemical systems, several reactivity descriptors have been proposed. In this work, electronic properties and biological reactivity studies of three compounds $\mathbf{2 e}$ (ortho-substituted), 2f (meta-substituted), and $\mathbf{2 g}$ (para-substituted) were carried out. Geometries of the compounds were optimized and bonding parameters were compared to the experimental data. Frontier molecule orbitals (HOMO and LUMO) and the energy values were computed. The global reactivity descriptors were examined to get an idea of the reactive nature of the compounds. NBO analysis was performed to investigate the stability of the molecules resulting from hyperconjugative interactions and charge delocalization. Natural population analysis (NPA) was also carried out. The putative biological activity spectra of the compounds were predicted.

It is believed that this kind of study will contribute to getting a fast knowledge of the chemical behavior of 2-hydroxyethyl substituted NHC salts. As proved by enzyme inhibition studies (Erdemir et al., 2018), these compounds can be a candidate as new drugs for therapy of some diseases such as osteoporosis, gastric and duodenal ulcers, glaucoma, mountain sickness, epilepsy or neurological disturbances.

\section{MATERIALS AND METHODS}

The synthesis and crystallization studies of the structures $\mathbf{2 e}, \mathbf{2 f}$, and $\mathbf{2 g}$ were performed by Prof. Dr. Yetkin Gök at İnönü University Scientific and Technology Center, and structural determinations were carried out at Dokuz Eylül University X-ray Crystallography Laboratory (Erdemir et al., 2018). The CCDC codes of the structures are 1568021 for $\mathbf{2 e}, 1568019$ for $\mathbf{2 f}$ and 1568020 for $\mathbf{2 g}$.

\section{Computational Procedure}

All the quantum chemical calculations were carried out at Density Functional Theory (DFT) method employing B3LYP/Lan12dz basis set using Gauss-View6 molecular visualization and Gaussian 09W program packages (Frisch et al., 2010; Dennington et al., 2016). The natural bonding orbital (NBO) calculations were performed using NBO 3.1 program as implemented in Gaussian 09W package to get detailed insight about the charge transfer, intramolecular interactions and investigate the delocalization or hyperconjugative interactions in the molecular systems of $\mathbf{2 e ,} \mathbf{2 f}$ and $\mathbf{2 g}$ (Glendening et al., 1995). The biological activity spectra of studied compounds were obtained by the PASS Online Program (Anonymous, 2014). 
A Theoretical Study of 2-hydroxyethyl Substituted NHC Precursors Containing ortho-, meta- and paramethylbenzyl: Global Reactivity Descriptors and Prediction of Biological Activities

\section{RESULTS AND DISCUSSION}

\section{Geometry Optimization of The Compounds}

The optimized ground state geometry of the compounds at DFT/B3LYP/Lanl2dz level of the theory and the superimposition of the experimental and calculated structures are shown in Figure 1. The correlations between the theoretical and experimental bonding parameters are displayed in Figure 2. As can be seen from Figure 1 that the best overlay of the experimental and theoretical structure occurs at $\mathbf{2 g}$. There are some discrepancies for $\mathbf{2 e}$ and $\mathbf{2 f}$, especially in the substituted methylbenzyl and hydroxyethyl moieties. It is clearly understood that the theoretical calculations of the isolated structure are carried out in the gas phase, while the experimental molecular structures are in a solid-state form likely caused these differences. Also, the experimental structures have $\mathrm{O}-\mathrm{H} \cdots \mathrm{I}$ type intermolecular interactions, which may cause discrepancies in the bonding parameters.
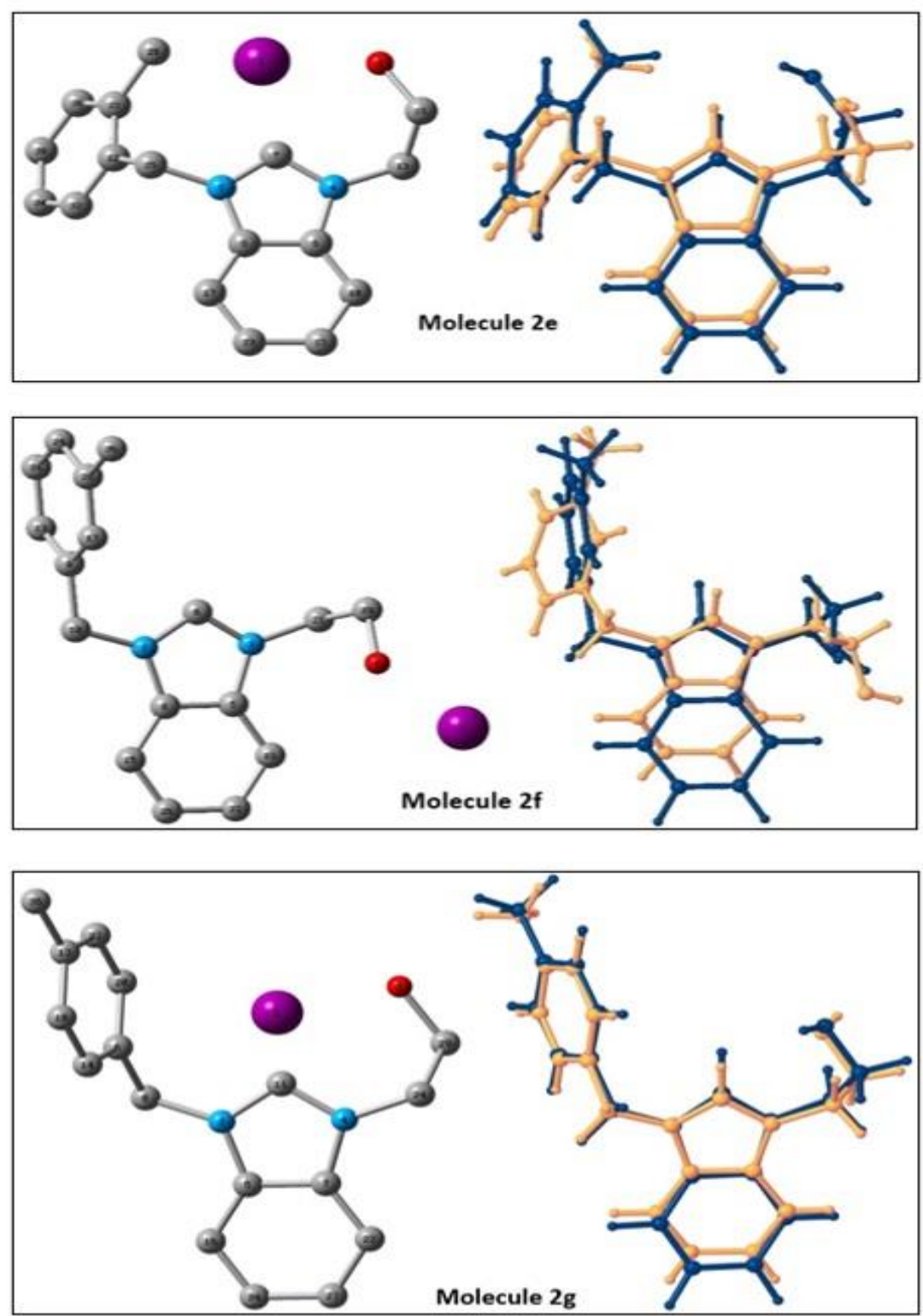

Figure.1 Atom-by-atom superimposition of the calculated structure (blue) and the crystal structure (orange) of the compounds $\mathbf{2 e}, \mathbf{2 f}$ and $\mathbf{2 g}$. 
A Theoretical Study of 2-hydroxyethyl Substituted NHC Precursors Containing ortho-, meta- and paramethylbenzyl: Global Reactivity Descriptors and Prediction of Biological Activities
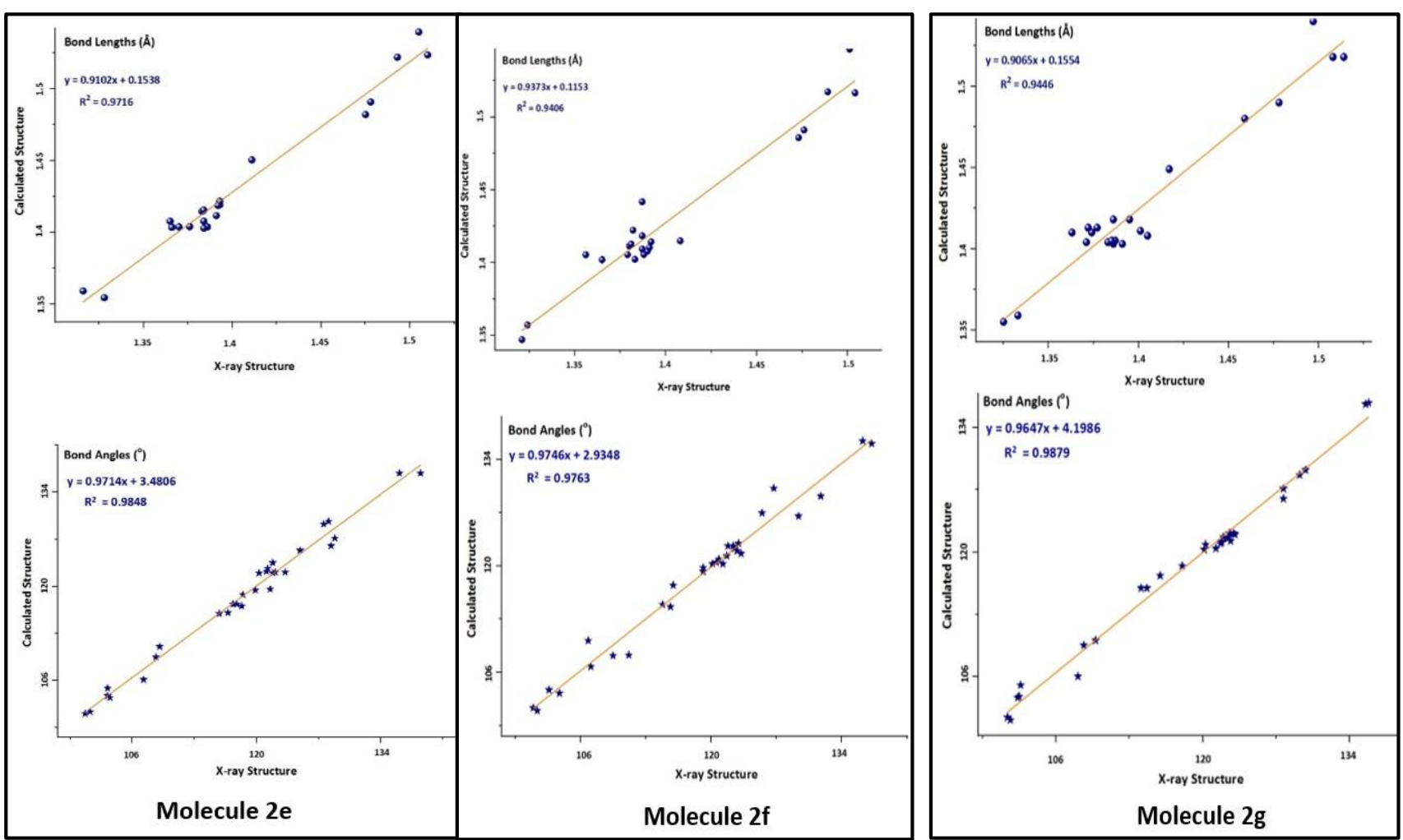

Figure.2 The correlations between the theoretical and experimental bonding parameters for the compounds $2 \mathbf{e}, \mathbf{2 f}$ and $\mathbf{2 g}$.

\section{Atomic Charges: Mullikan Population Analysis (MPA) and Natural Population Analysis (NPA)}

Mulliken population analysis (MPA) and natural population analysis (NPA) have an important role in the application of quantum chemical calculations. The atomic charge distribution of acceptor and donor atoms in molecules affects molecular polarizability, dipole moment, electronic structure, aciditybasicity behavior and a lot of properties of a molecular system and electrostatic potential surfaces (Balachandran and Primala, 2012; Lakshmi and Balachandran, 2013). MPA and NPA analyses of the structures were performed using B3LYP/Lanl2dz level of calculation and the list of all calculated atomic charges is given in Table 1. They were obtained from Natural Bond Orbital (NBO) results. The analyses reveal the presence of electrophilic and nucleophilic atomic charges. According to the Table, NPA's net charges are mostly longer than Mulliken charges. The iodide anions of the compounds display high nucleophilic behavior with their negative donor atomic charges, while the $\mathrm{C}_{\text {carbene}}-\mathrm{H}$ and The $\mathrm{O}-\mathrm{H}$ protons have the highest positive charge values. So, iodide anions attack these hydrogen atoms, which is the most reactive site of the molecules.

\section{Frontier Molecular Orbitals (FMOs) and Molecular Electrostatic Potential (MEP)}

The FMOs theory involving HOMO and LUMO is one of the most important theories to introduce the chemical stability of a molecule (Gunasekaran et al., 2008). The highest occupied molecular orbital (HOMO) and the lowest unoccupied molecular orbital (LUMO) energies provide deep information about the energy distribution and energetic behavior of compounds and complexes. The high value of Еномо shows how easy of donating an electron to the unoccupied orbital of the receptor molecule, while the small value of ELUMO indicates the small resistance to accept electrons so that it can easily accept electrons. The energy gap $(\Delta)$ displays the chemical reactivity and kinetic stability of a molecule. A large frontier orbital gap describes a hard molecule and much less polarizability. The soft systems have a small frontier orbital gap and highly polarizable. Also, a large HOMO-LUMO gap implies high molecular 

methylbenzyl: Global Reactivity Descriptors and Prediction of Biological Activities

stability and aromaticity low reactivity in chemical reactions, while a small HOMO-LUMO gap is related to anti-aromaticity. The distributions of the HOMO and LUMO orbitals computed at the B3LYP/Lanl2dz level for three molecules are displayed in Figure 3. The compounds have 75 occupied MOs. For all molecules, the HOMOs are localized on the I ions, while the LUMOs are distributed over the benzimidazole fragment. The HOMO-LUMO energy gap $(\Delta)$ of the molecules are given in Table 2. As can be seen, $\mathbf{2} \mathbf{f}$ has the narrowest frontier orbital gap of all molecules.

Table 1. Mulliken population analysis (MPA) and Natural population analysis (NPA) from NBO calculation.

\begin{tabular}{|c|c|c|c|c|c|c|c|c|}
\hline \multicolumn{3}{|c|}{$2 \mathrm{e}$} & \multicolumn{3}{|c|}{$2 f$} & \multicolumn{3}{|c|}{$2 \mathrm{~g}$} \\
\hline Atom & Mulliken & NPA & Atom & Mulliken & NPA & Atom & Mulliken & NPA \\
\hline I1 & -0.6946 & -0.7973 & I1 & -0.7736 & -0.8646 & I1 & -0.7024 & -0.8014 \\
\hline $\mathbf{O 2}$ & -0.5037 & -0.8251 & O4 & -0.4735 & -0.8113 & $\mathbf{O 2}$ & -0.4991 & -0.8226 \\
\hline N4 & -0.1652 & -0.4049 & $\mathbf{N} 2$ & -0.1707 & -0.3972 & N3 & -0.1417 & -0.3900 \\
\hline N5 & -0.1184 & -0.3877 & N3 & -0.1211 & -0.3745 & $\mathbf{N 4}$ & -0.1597 & -0.4050 \\
\hline C6 & 0.2514 & 0.1643 & C5 & 0.3224 & 0.1699 & C5 & 0.2768 & 0.1672 \\
\hline C7 & -0.1126 & 0.3471 & C6 & -0.0806 & 0.3279 & C6 & 0.4435 & -0.0721 \\
\hline C9 & 0.2673 & 0.1673 & C8 & 0.2387 & 0.1566 & C7 & 0.2526 & 0.1644 \\
\hline $\mathrm{C10}$ & -0.3229 & -0.2316 & C9 & 0.4052 & -0.0647 & C8 & -0.5158 & -0.2127 \\
\hline C12 & 0.3226 & -0.0593 & C10 & -0.4868 & -0.2111 & C11 & -0.1124 & 0.3439 \\
\hline $\mathrm{C} 13$ & -0.3140 & -0.2143 & C13 & -0.3896 & -0.2230 & C13 & 0.4404 & 0.0044 \\
\hline C15 & -0.2015 & -0.2002 & C15 & -0.3100 & -0.2527 & C14 & -0.3705 & -0.2050 \\
\hline C17 & -0.3023 & -0.2273 & C17 & -0.5427 & -0.2256 & C16 & -0.3199 & -0.2261 \\
\hline C19 & -0.2474 & -0.0645 & C19 & -0.2761 & -0.1862 & C18 & -0.4105 & -0.2179 \\
\hline $\mathrm{C} 22$ & 0.2457 & 0.0028 & C21 & -0.3741 & -0.2297 & $\mathrm{C20}$ & -0.3929 & -0.2011 \\
\hline $\mathrm{C} 23$ & -0.2098 & -0.1994 & C24 & -0.3503 & -0.2074 & $\mathrm{C22}$ & -0.3193 & -0.2317 \\
\hline $\mathrm{C} 25$ & -0.5800 & -0.2143 & $\mathrm{C} 26$ & -0.1953 & -0.1874 & $\mathrm{C} 24$ & -0.3156 & -0.2148 \\
\hline $\mathrm{C} 28$ & -0.7746 & -0.6659 & $\mathrm{C} 28$ & 0.4290 & 0.0125 & $\mathrm{C27}$ & -0.2028 & -0.2003 \\
\hline C32 & -0.3588 & -0.2067 & C29 & -0.2543 & -0.0620 & $\mathrm{C29}$ & -0.2485 & -0.0637 \\
\hline C34 & -0.2434 & -0.2135 & C32 & -0.2187 & -0.1933 & C32 & -0.3624 & -0.2088 \\
\hline C36 & -0.3376 & -0.2094 & C34 & -0.2146 & -0.1925 & C34 & -0.2045 & -0.2003 \\
\hline C38 & -0.2299 & -0.1993 & C36 & -0.7547 & -0.6523 & C36 & -0.7533 & -0.6516 \\
\hline H3 & 0.3357 & 0.4899 & H7 & 0.3108 & 0.2461 & H9 & 0.1976 & 0.2248 \\
\hline H8 & 0.3787 & 0.2741 & H11 & 0.2401 & 0.2409 & H10 & 0.2931 & 0.2653 \\
\hline H11 & 0.2369 & 0.2307 & H12 & 0.2399 & 0.2386 & H12 & 0.3818 & 0.2800 \\
\hline H14 & 0.2390 & 0.2366 & H14 & 0.2418 & 0.2235 & H15 & 0.2214 & 0.2149 \\
\hline H16 & 0.2322 & 0.2303 & H16 & 0.2397 & 0.2288 & H17 & 0.2411 & 0.2333 \\
\hline H18 & 0.2362 & 0.2319 & H18 & 0.2482 & 0.2230 & H19 & 0.2261 & 0.2172 \\
\hline H20 & 0.2225 & 0.2135 & H20 & 0.2959 & 0.2693 & H21 & 0.2870 & 0.2469 \\
\hline H21 & 0.1982 & 0.2060 & H22 & 0.1921 & 0.2235 & $\mathbf{H} 23$ & 0.2361 & 0.2304 \\
\hline H24 & 0.2320 & 0.2305 & H23 & 0.2781 & 0.2629 & H25 & 0.1950 & 0.2223 \\
\hline H26 & 0.2941 & 0.2644 & H25 & 0.2384 & 0.2250 & H26 & 0.2375 & 0.2367 \\
\hline H27 & 0.2095 & 0.2319 & H27 & 0.2321 & 0.2304 & H28 & 0.2317 & 0.2299 \\
\hline H29 & 0.2492 & 0.2386 & H30 & 0.2251 & 0.2169 & H30 & 0.1977 & 0.2056 \\
\hline H30 & 0.2207 & 0.2361 & H31 & 0.1792 & 0.1889 & H31 & 0.2211 & 0.2121 \\
\hline H31 & 0.2180 & 0.2289 & H33 & 0.2487 & 0.2402 & H33 & 0.2324 & 0.2230 \\
\hline H33 & 0.2113 & 0.2101 & H35 & 0.2321 & 0.2284 & H35 & 0.2322 & 0.2303 \\
\hline H35 & 0.2245 & 0.2212 & H37 & 0.2273 & 0.2365 & H37 & 0.2229 & 0.2325 \\
\hline H37 & 0.2292 & 0.2194 & H38 & 0.2207 & 0.2332 & H38 & 0.2175 & 0.2296 \\
\hline H39 & 0.2257 & 0.2218 & H39 & 0.2172 & 0.2257 & H39 & 0.2079 & 0.2204 \\
\hline H40 & 0.1963 & 0.2232 & H40 & 0.3325 & 0.4870 & H40 & 0.3379 & 0.4902 \\
\hline
\end{tabular}

The molecular electrostatic potential (MEP) is related to the electron density. It is an important descriptor for understanding the reactive behavior in both electrophilic and nucleophilic reactions and hydrogen bonding reactions (Okulik and Jubert, 2005). In the MEP profile, the blue colored areas represent the positive potential regions, which demonstrates the strongest attraction, whereas the red colors are the maximum negative potential sections, indicates the repulsion. In the present study, the MEP diagrams 
A Theoretical Study of 2-hydroxyethyl Substituted NHC Precursors Containing ortho-, meta- and paramethylbenzyl: Global Reactivity Descriptors and Prediction of Biological Activities

of the molecules are illustrated in Figure 4. The negative regions are associated with oxygen atoms and iodide ions. It can be suggested that the most preferred regions for the electrophilic attack are around these regions. The net charges of these atoms (see Table 1) confirmed the MEP output. On the other hand, the most maximum positive regions are localized on the remainder of the molecules.
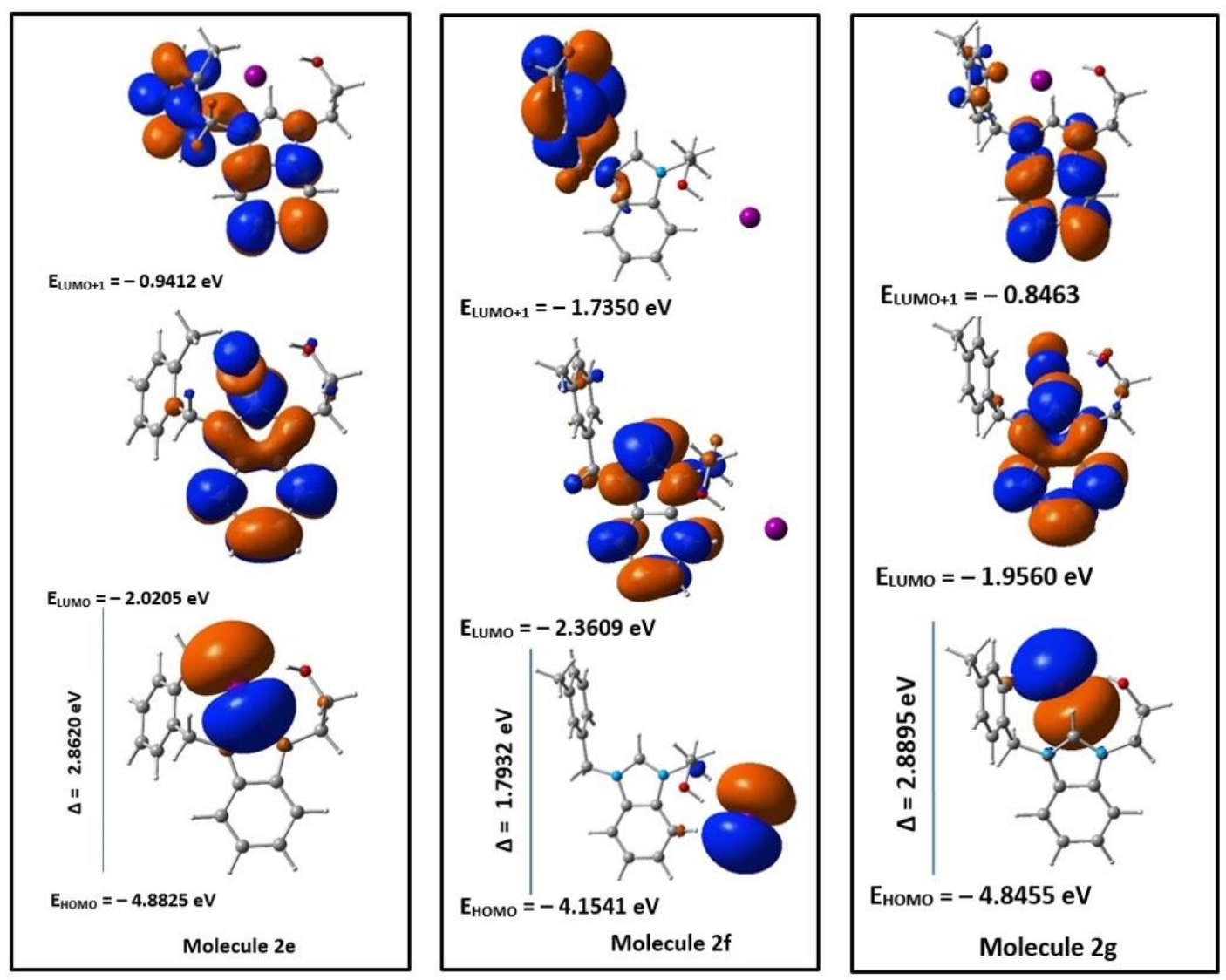

Figure 3. Electronic distribution of HOMO and LUMO energy levels for the compounds $2 \mathbf{2 e}, \mathbf{2} \mathbf{f}$ and $\mathbf{2 g}$.

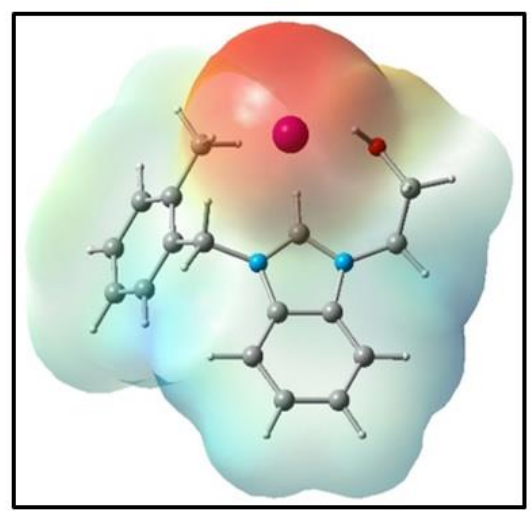

Molecule 2e

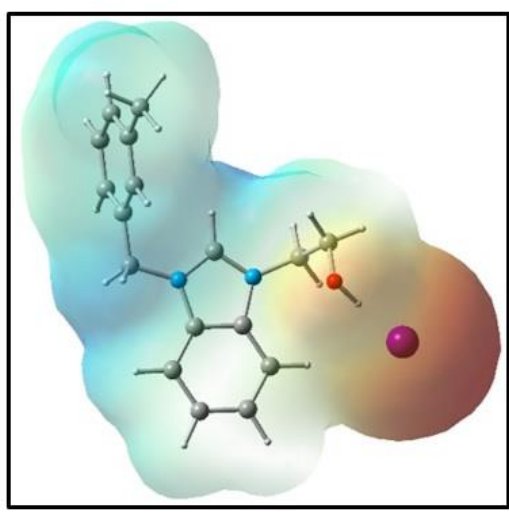

Molecule $2 f$

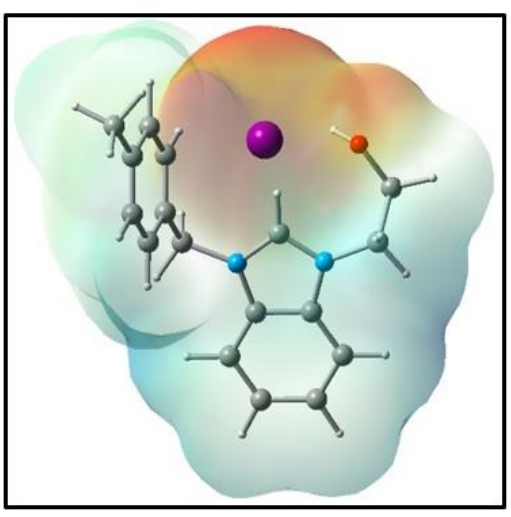

Molecule 2g

Figure 4. The MEP diagram of the molecules. The maximum positive regions are shown in blue, whereas the maximum negative ones are in red color. 
A Theoretical Study of 2-hydroxyethyl Substituted NHC Precursors Containing ortho-, meta- and paramethylbenzyl: Global Reactivity Descriptors and Prediction of Biological Activities

\section{Natural Bond Orbital Analysis}

NBO analysis gives an important insight into the interactions in both filled and virtual orbital spaces that could enhance the analysis of intra- and inter-molecular interactions (Meenakshi, 2017). The interactions depend on the energy difference between interacting orbitals, and the strong interactions occur between the donor and acceptor. In order to calculate the stabilization energy for each donor (i) and acceptor $(\mathrm{j}$ ) within $\mathrm{i} \rightarrow \mathrm{j}$ delocalization, the second-order perturbation analysis of the Fock matrix is used. The estimated energy can be determined as; $E(2)=\Delta E_{i j}=q_{i} \frac{F_{i, j}^{2}}{E_{j}-E_{i}}$; where $q_{i}$ is donor orbital occupancy, $E_{i}$ and $E_{j}$ are diagonal elements and $F_{i j}$ is the off-diagonal NBO Fock matrix element. The larger the $\mathrm{E}(2)$ value implies the more intensive interaction between electron donors and acceptors (Xavier and Gobinath, 2012). The natural bond orbitals' (NBO) calculations for the structures $\mathbf{2 e}, \mathbf{2 f}$ and 2g were performed at the DFT/B3LYP/Lanl2dz method. The stabilization energies of the most important interactions between donor and acceptor are given in Table 2. According to the table, the strongest interactions $\left(\pi^{*} \rightarrow \pi^{*}\right)$ occur in the $N$-heterocyclic carbene (NHC) ligand for all molecules. In the benzene ring of the NHC ring system, interactions between the pi-electrons of the carbon atoms have the highest energy. The electron donations from a lone-pair orbital on the nitrogen atoms of $N$-benzimidazole rings have also high stabilization energies.

Table 2. The Second Order Perturbation Theory Analysis Results of the Fock Matrix in NBO Basis for 2e, 2f and $\mathbf{2 g}$ at B3LYP/6-31G* level of the theory.

\begin{tabular}{lllll}
\hline Donor (i) & Acceptor $(\mathbf{j})$ & $\mathbf{E}(\mathbf{2}) \mathbf{k J ~ m o l}^{\mathbf{1}}$ & $\mathbf{E}_{\mathbf{j}}-\mathbf{E}_{\mathbf{i}}(\mathbf{a . u})$ & $\mathbf{F}_{\mathbf{i}, \mathbf{j}}(\mathbf{a . u})$ \\
\hline $\mathbf{2 e}$ & & & & \\
\hline$\pi^{*}$ C6-C9 & $\pi^{*}$ C10-C15 & 204.22 & 0.02 & 0.082 \\
$\pi^{*}$ C6-C9 & $\pi^{*}$ C17-C23 & 186.56 & 0.02 & 0.082 \\
LP(1) N5 & $\pi^{*}$ N4-C7 & 83.64 & 0.21 & 0.120 \\
LP(1) N5 & $\pi^{*}$ C6-C9 & 34.79 & 0.28 & 0.089 \\
\hline $\mathbf{2 f}$ & & & & \\
\hline$\pi^{*}$ C9-C13 & $\pi^{*}$ C24-C34 & 288.99 & 0.01 & 0.082 \\
$\pi^{*}$ C9-C13 & $\pi^{*}$ C17-C28 & 221.31 & 0.01 & 0.080 \\
$\pi^{*}$ C5-C8 & $\pi^{*}$ C15-C26 & 168.16 & 0.02 & 0.080 \\
$\pi^{*}$ C15-C26 & $\pi^{*}$ C19-C32 & 113.56 & 0.02 & 0.080 \\
LP(1) N3 & $\pi^{*}$ N2-C6 & 92.42 & 0.20 & 0.121 \\
\hline $\mathbf{2 g}$ & & & & 0.082 \\
\hline$\pi^{*}$ C5-C7 & $\pi^{*}$ C22-C27 & 206.50 & 0.02 & 0.082 \\
$\pi^{*}$ C5-C7 & $\pi^{*}$ C16-C34 & 189.68 & 0.02 & 0.119 \\
LP(1) N3 & $\pi^{*}$ N4-C11 & 82.33 & 0.21 & \\
\hline
\end{tabular}

\section{Global Reactivity Descriptors Calculation}

DFT method provides an important vision on molecular structure stability and reactivity (Choudhary et al., 2019). The global reactivity descriptors calculated using the DFT method play an essential and reliable role to understand the biological activities in many studies. The global hardness $(\eta)$ measures the resistance to change in electron density. Chemical potential $(\mu)$ measures the escaping tendency of an electron. If the chemical potential is greater, then the compound is less stable or more 
reactive. Electronegativity $(\chi)$ describes the ability of a molecule not to let out its electrons. Electrophilicity index $(\omega)$ characterizes the electrophilic power of the molecule, it measures the tendency of the species to accept electrons. Softness $(S)$ is the inverse of hardness, the stability of a molecule decreases with the increasing global softness of a molecule. The maximum charge transfer $\left(\Delta N_{\max }\right)$, describes the propensity of the system to acquire additional electronic charge from the environment (Mendoza-Huizar, 2014). These global reactivity parameters can be defined as:

$$
\begin{array}{lll}
\mu=-\frac{(I+A)}{2} & \chi=-\mu & \eta=\frac{(I-A)}{2} \\
\omega=\frac{\mu^{2}}{2 \eta} & S=\frac{1}{2 \eta} & \Delta N_{\max }=-\frac{\mu}{\eta}
\end{array}
$$

It could be seen in Table 3 that the most reactive molecule is $\mathbf{2 f}$ with its smallest energy gap. A smaller energy gap indicates a softer compound. The softness $(S)$ of the $\mathbf{2} \mathbf{f}$ is the highest among the other molecules, so the hardness descriptor is the smallest. Also, its chemical potential $(\mu)$ and electrophilicity index $(\omega)$ values are the greatest and the maximum charge transfer capability $\left(\Delta N_{\max }\right)$ is the highest of all molecules.

Table 3. Global descriptors of chemical reactivity of the NHC precursors

\begin{tabular}{llll}
\hline$(\mathbf{e V})$ & $\mathbf{2 e}$ & $\mathbf{2 f}$ & $\mathbf{2 g}$ \\
\hline $\mathbf{E}_{\text {Hомо }}(-\mathbf{I})$ & -4.8825 & -4.1541 & -4.8455 \\
$\mathbf{E}_{\text {LUMо }}(-\mathbf{A})$ & -2.0205 & -2.3609 & -1.9560 \\
$\mathbf{E}_{\text {gap }}$ & 2.8620 & 1.7932 & 2.8895 \\
Electronegativity $\boldsymbol{\chi}$ & 3.4515 & 3.2575 & 3.4008 \\
Chemical hardness $\boldsymbol{\eta}$ & 1.4310 & 0.8966 & 1.4448 \\
Electronic chemical potential $\boldsymbol{\mu}$ & -3.4515 & -3.2575 & -3.4008 \\
Electrophilicity index $\boldsymbol{\omega}$ & 4.1624 & 5.9175 & 4.0026 \\
Softness S & 0.3490 & 0.5577 & 0.3461 \\
Maximum charge transfer capability $\mathbf{\Delta N}_{\max }$ & 2.4119 & 3.6332 & 2.3538 \\
\hline
\end{tabular}

\section{Theoretical Assessment of Biological Activity with PASS}

The PASS (Prediction of Activity Spectra for Substances) computer program is an estimation tool, which allows predicting the probable profile of biological activity of a drug-like organic compound based on its structural formula. The average accuracy of prediction is about $95 \%$ according to leave-oneout-cross validation (LOOCV) estimation (Filimonov and Poroikov, 2008; Filimonov et al., 2014).

The biological activity spectra of the 2-hydroxyethyl substituted benzimidazolium salts were theoretically obtained by the PASS Online program and the analysis results were enlisted in Table 4. According to the data, all compounds are very likely to be Substance P antagonist, anti-inflammatory, analgesic, non-opoid analgesic, anaphylatoxin receptor antagonist, and with corresponding $\mathrm{P}_{\mathrm{a}}$ values, which are higher than 0.7 . In our previous study, experimental biological activity behaviors of these structures were investigated (Erdemir et al., 2018). PASS online results also reveal that these compounds have some potential biological activities, may be a potential source for the future development of medicines. 
A Theoretical Study of 2-hydroxyethyl Substituted NHC Precursors Containing ortho-, meta- and paramethylbenzyl: Global Reactivity Descriptors and Prediction of Biological Activities

Table 4. Biological activity assessment using PASS online software.

\begin{tabular}{lcccccc}
\hline Activity & \multicolumn{2}{c}{$\mathbf{2 e}$} & \multicolumn{2}{c}{} & \multicolumn{2}{c}{$\mathbf{2 g}$} \\
\hline & $\boldsymbol{P}_{\boldsymbol{a}}$ & $\boldsymbol{P}_{\boldsymbol{i}}$ & $\boldsymbol{P}_{\boldsymbol{a}}$ & $\boldsymbol{P}_{\boldsymbol{i}}$ & $\boldsymbol{P}_{\boldsymbol{a}}$ & $\boldsymbol{P}_{\boldsymbol{i}}$ \\
\cline { 2 - 7 } Substance P antagonist & 0.862 & 0.002 & 0.853 & 0.002 & 0.872 & 0.002 \\
Antiinflammatory & 0.837 & 0.005 & 0.823 & 0.005 & 0.828 & 0.005 \\
Analgesic & 0.832 & 0.005 & 0.895 & 0.004 & 0.899 & 0.004 \\
Analgesic, non-opioid & 0.794 & 0.005 & 0.854 & 0.004 & 0.855 & 0.004 \\
Anaphylatoxin receptor antagonist & 0.707 & 0.023 & - & - & 0.707 & 0.023 \\
Antieczematic & - & - & - & - & 0.702 & 0.045 \\
\hline
\end{tabular}

\section{CONCLUSION}

In this work, theoretical aspects of three 2-hydroxyethyl substituted $N$-heterocyclic carbene (NHC) precursors containing ortho-, meta- and para- methylbenzyl fragments were investigated. Geometric parameters were calculated and compared to the experimental results. Most of the results were found to be compatible with the crystal structures. The frontier molecular orbitals were visualized and the HOMO-LUMO energy gap revealed the charge transfer interactions involved in the compounds. Global reactivity descriptors were also computed to point out the activation of the molecules and $\mathbf{2} \mathbf{f}$ was found to be the most reactive molecule. In order to investigate the stability of the molecules resulting from hyperconjugative interactions and charge delocalization, Natural bond orbital (NBO) analysis was used. Biological activity predictions showed that all structures have especially a high substance $\mathrm{P}$ antagonist, antiinflammatory, and analgesic activities.

\section{ACKNOWLEDGEMENTS}

Thanks Assoc. Prof. Dr. Muhittin Aygün for the use of the Gaussian 09W/Gauss View package program.

\section{REFERENCES}

Anonymous, 2014. Prediction of the Biological Activity Spectra of Organic Compounds Using the Pass Online Web Resource. http://www.way2drug.com/PASSOnline/.

Balachandran V, Parimala K, 2012. Tautomeric purine forms of 2-amino-6-chloropurine $\left(\mathrm{N}_{9} \mathrm{H}_{10}\right.$ and $\left.\mathrm{N}_{7} \mathrm{H}_{10}\right)$ : Structures, vibrational assignments, NBO analysis, hyperpolarizability, HOMO-LUMO study using B3 based density functional calculations, Spectrochimica Acta A 96:340-351.

Chattaraj PK, Nath S, Maiti B, 2003. Computational Medicinal Chemistry for Drug Discovery. Marcel Dekker. New York.

Choudhary VK, Bhatt AK, Dash D, Sharma N, 2019. DFT Calculations on Molecular Structures, HOMOLUMO Study, Reactivity Descriptors and Spectral Analyses of Newly Synthesized Diorganotin (IV) 2-Chloridophenylacetohydroxamate Complexes, Journal of Computational Chemistry 40:2354-2363. Dennington R, Keith TA, Millam JM, 2016. GaussView, Version 6, Semichem Inc. Shawnee Mission. KS.

Dragutan V, Dragutan I, Delaude L, Demonceau A, 2007. NHC-Ru complexes-Friendly catalytic tools for manifoldchemical transformations. Coordination Chemistry Reviews 251:765-794.

Erdemir F, Barut Celepci D, Aktaş A, Taslimi P, Gök Y, Karabıyık H, Gülçin İ, 2018. 2-Hydroxyethyl substituted NHC precursors: Synthesis, characterization, crystal structure and carbonic anhydrase, aglycosidase, butyrylcholinesterase, and acetylcholinesterase inhibitory properties, Journal of Molecular Structure 1155:797-806.

Filimonov DA, Lagunin AA, Gloriozova TA, Rudik AV, Druzhilovskii DS, Pogodin PV, Poroikov VV, 2014. Prediction of the Biological Activity Spectra of Organic Compounds Using the Pass Online Web Resource, Chemistry of Heterocyclic Compounds 50:444-457. 

methylbenzyl: Global Reactivity Descriptors and Prediction of Biological Activities

Filimonov DA, Poroikov VV, 2008. RSC Publishing. Cambridge. 182-216.

Frisch MJ, Trucks GW, Schlegel HB, Scuseria GE, Robb MA, Cheeseman JR, Scalmani G, Barone V, Petersson GA, Nakatsuji H, Li X, Caricato M, Marenich A, Bloino J, Janesko BG, Gomperts R, Mennucci B, Hratchian HP, Ortiz JV, Izmaylov AF, Sonnenberg JL, Williams-Young D, Ding F, Lipparini F, Egidi F, Goings J, Peng B, Petrone A, Henderson T, Ranasinghe D, Zakrzewski VG, Gao J, Rega N, Zheng G, Liang W, Hada M, Ehara M, Toyota K, Fukuda R, Hasegawa J, Ishida M, Nakajima T, Honda Y, Kitao O, Nakai H, Vreven T, Throssell K, Montgomery JA, Peralta JJE, Ogliaro F, Bearpark M, Heyd JJ, Brothers E, Kudin KN, Staroverov VN, Keith T, Kobayashi R, Normand J, Raghavachari K, Rendell A, Burant JC, Iyengar SS, Tomasi J, Cossi M, Millam JM, Klene M, Adamo C, Cammi R, Ochterski JW, Martin RL, Morokuma K, Farkas O, Foresman JB, and Fox DJ, 2010. Gaussian 09 Revision B.01. Gaussian, Inc. Wallingford CT.

Glendening ED, Badenhoop JK, Reed AE, Carpenter JE, Weinhold F, 1995. NBO Version 3.1. Theoretical Chemistry Institute. University of Wisconsin. Maddison.

Gunasekaran S, Balaji RA, Kumeresan S, Anand G, Srinivasan S, 2008. Experimental and theoretical investigations of spectroscopic properties of $\mathrm{N}$-acetyl-5-methoxytryptamine, Canadian Journal of Analytical Sciences and Spectroscopy 53:149-162.

Hopkinson MN, Richter C, Schedler M, Glorius F, 2014. An overview of N-heterocyclic carbenes. Nature 510:485-496.

Lakshmi A, Balachandran V, 2013. Rotational isomers, NBO and spectral analyses of N-(2-hydroxyethyl) phthalimide based on quantum chemical calculations, Journal of Molecular Structure 1033:40-50.

Meenakshi R, 2017. Spectral investigations, DFT based global reactivity descriptors, Inhibition efficiency and analysis of 5-chloro-2-nitroanisole as $\pi$-spacer with donor-acceptor variations effect for DSSCs performance, Journal of Molecular Structure 1127:694-707.

Mendoza-Huizar LH, 2014. Chemical Reactivity of Quinmerac Herbicide Through the Fukui Function, Acta Chimica Slovenica 61:694-702.

Nirmala M, Viswanathamurthi P, 2016. Design and synthesis of ruthenium(II) OCO pincer type NHC complexes and their catalytic role towards the synthesis of amides, Journal of Chemical Sciences 128:9-21.

Okulik N, Jubert AH, 2005. Theoretical Analysis of the Reactive Sites of Non-steroidal Anti-inflammatory Drugs, Internet Electronic Journal of Molecular Design 4:17-21.

Sarı Y, Aktaş A, Taslimi P, Gök Y, Gülçin İ, 2018. Novel N-propylphthalimide- and 4-vinylbenzylsubstituted benzimidazole salts: Synthesis, characterization, and determination of their metal chelating effects and inhibition profiles against acetylcholinesterase and carbonic anhydrase enzymes. Journal of Biochemical and Molecular Toxicology 32:e22009.

Xavier RJ, Gobinath E, 2012. FT-IR, FT-Raman, $a b$ initio and DFT studies, HOMO-LUMO and NBO analysis of 3-amino-5-mercapto-1,2,4-triazole, Spectrochimica Acta A. Molecular and Biomolecular Spectroscopy 86:242-251.

Zou T, Lok CN, Wan PK, Zhang ZF, Fung SK, Che CM, 2018. Anticancer metal-N heterocyclic carbene complexes of gold, platinum and palladium. Current Opinion in Chemical Biology 43:30-36. 